\title{
Normal and Disordered Formation of the Cerebral Cortex : Normal Embryology, Related Molecules, Types of Migra- tion, Migration Disorders
}

\author{
Ji Yeoun Lee, M.D., Ph.D., ${ }^{1,2}$ \\ Department of Anatomy and Cell Biology, Seoul National University College of Medicine, Seoul, Korea \\ Division of Pediatric Neurosurgery, ${ }^{2}$ Seoul National University Children's Hospital, Seoul, Korea
}

The expansion and folding of the cerebral cortex occur during brain development and are critical factors that influence cognitive ability and sensorimotor skills. The disruption of cortical growth and folding may cause neurological disorders, resulting in severe intellectual disability and intractable epilepsy in humans. Therefore, understanding the mechanism that regulates cortical growth and folding will be crucial in deciphering the key steps of brain development and finding new therapeutic targets for the congenital anomalies of the cerebral cortex. This review will start with a brief introduction describing the anatomy of the brain cortex, followed by a description of our understanding of the proliferation, differentiation, and migration of neural progenitors and important genes and molecules that are involved in these processes. Finally, various types of disorders that develop due to malformation of the cerebral cortex will be discussed.

Key Words : Cerebral cortex · Embryology · Malformations of cortical development.

\section{ANATOMY OF THE CEREBRAL CORTEX}

More than $90 \%$ of the surface area of the human cerebral cortex is composed of the 6-layered neocortex. Roughly twothirds of the cortical surface is folded and located inside the sulci. Cortical folding not only enables a reduction of brain volume but also optimizes brain connectivity ${ }^{26)}$. The thickness of the neocortex ranges from 1 to $3 \mathrm{~mm}$, with thicker sections at the top of the gyri than deep inside the sulci ${ }^{44)}$. Regarding the cell composition of the cerebral cortex, pyramidal neurons (glutamatergic, excitatory), which establish long circuits, are the most abundant (80\%). Interneurons, on the other hand, are gamma-aminobutyric acid-ergic (GABAergic), inhibitory neurons that establish local, intracortical connections between pyramidal neurons. The neurons are arranged primarily in a columnar unit but become organized in layers due to the horizontal, intracortical development of cortical fibers ${ }^{4)}$.

The basic six layers are as follows.

1) layer I : molecular layer, contains local connecting fibers.

2) layer II : external granular layer, receives corticocortical afferents (association and commissural fibers).

3) layer III : external pyramidal layer, sends corticocortical

- Received : April 15, $2019 \bullet$ Revised : April 28, $2019 ・$ Accepted : April 29, 2019

- Address for reprints : Ji Yeoun Lee, M.D., Ph.D.

Department of Anatomy and Cell Biology, Seoul National University College of Medicine, Division of Pediatric Neurosurgery, Seoul National University Children's Hospital, 101 Daehak-ro, Jongno-gu, Seoul 03080, Korea

Tel : +82-2-740-8205, Fax : +82-2-745-3489, E-mail : ddang1@snu.ac.kr

This is an Open Access article distributed under the terms of the Creative Commons Attribution Non-Commercial License (http://creativecommons.org/licenses/by-nc/4.0) which permits unrestricted non-commercial use, distribution, and reproduction in any medium, provided the original work is properly cited. 
efferents (association and commissural fibers).

4) layer IV : internal granular cell layer, receives thalamocortical afferents.

5) layer $\mathrm{V}$ : internal pyramidal layer, sends the cortico-subcortical efferents (to the striatum, brainstem, and cord).

6) layer VI : Fusiform or multiform layer, sends corticothalamic efferents.

\section{NORMAL DEVELOPMENT OF THE CORTEX}

The cerebral cortex is formed from neuroepithelial cells (NECs). In humans, NEC proliferation begins in the 4th week of development in the neural plate. NECs proliferate in a symmetric fashion (one stem cell divides into two stem cells) until neural tube closure is complete ${ }^{9)}$. Afterwards, proliferation changes to asymmetric division in which one stem cell produces one stem cell and one neuron. The differentiated neurons are located in the periphery (primordial plexiform layer or preplate $[\mathrm{PP}]$ ), and as a consequence, the stem cells are placed in the deep germinative zone called the ventricular zone $(\mathrm{VZ})^{54)}$. In early developmental stages when the distance between the VZ and PP is short, the neurons move by somal translocation (nucleokinesis). Nucleokinesis occurs by the neuron extending a process toward the PP meningeal surface, and the nucleus moves toward the surface as the ventricular process shortens and is detached from the ventricle. CajalRetzius cells are one of the neurons in the PP that establish the first extracortical connections and play a major role in controlling the migration of neurons in the cortical plate (CP). The PP is divided into two layers : the superficial marginal zone (MZ) and the subcortical layer of the subplate (SP). The MZ contains Reelin-positive Cajal-Retzius cells, and the SP contains Reelin-negative Cajal-Retzius cells ${ }^{28,34)}$.

New-born excitatory, pyramidal neurons must migrate from the VZ where they are born, to near the surface of the cortex. This migration is accomplished through a process called radial migration ${ }^{41}$. Radial migration uses radial glial fibers of radial glial cells (RGCs) as a scaffold. RGCs are neuroepithelial progenitors that form bipolar radial fibers between the ventricular and meningeal surfaces. The newly formed neurons travel along the radial glial fiber in the direction perpendicular to the cortical surface and are induced to detach from the radial glia. The cell-cell interaction between the trav- elling neuron and RGC is under tight molecular control, and also affected by external signals such as Reelin provided by Cajal-Retzius cells. The trajectory of the fibers is a key factor in defining the migratory route and the final location of the new neurons along the cortical surface. The cells that leave the ventricular zone in the early stages of development settle in the deep layers of the cortex. The cells that exit the ventricular zone at later times travel longer distances, passing over previously born neurons, and settle in the superficial layers of the cortex $^{2,15,35)}$. This system explains the inside-out pattern of the cortical layers.

One of the major forces of the migration of neurons on RGCs is microtubular assembly and function. As a neuron wraps around the shaft of an RGC using its leading process, the nucleus of the cell moves within the cytoplasm of the leading process. The leading process slowly extends, and the nucleus follows in a rather stepwise fashion. The conduit for nuclear movement in the cytoplasm is a system of microtubules and centrosome-like structures termed the basal body. Another important player in neuronal migration along RGCs is adhesive interactions between cells, as adhesive receptors such as integrins promote neuronal extension on the scaffold ${ }^{36)}$.

Along with their role as a guiding scaffold, RGCs have been shown to act as progenitor cells that generate both neurons and astrocytes. These cells undergo asymmetric division in the VZ, producing another RGC and a neural progenitor ${ }^{40)}$. The neural progenitors move to the SVZ (subventricular zone) and become multipolar, establishing multiple cellular contacts. Then, the neural progenitors move tangentially to detach from the radial glia and scatter throughout the SVZ ${ }^{53}$.

Interneurons move by another mode of migration in the developing cortex, tangential migration, in close association with the radial migration of the pyramidal neurons. The major cellular substrate seems to be the axonal projections that connect pre-existing neurons. Tangential migration follows specific navigation routes. Interneurons are generated in the medial ganglionic eminence and travel parallel to the surface of the hemisphere toward the cortex. From the lateral ganglionic eminence, the interneurons rostrally migrate and contribute to the interneurons of the olfactory bulb ${ }^{28,44}$. During this process, the interneurons are speculated to acquire laminar address or positional information. The interaction of some interneurons with some pyramidal neurons during their migration may allow for the transmission of such positional information. Hence, this type of migration may 
have evolved as a mechanism for increasing the complexity of neuronal circuits $^{27,34)}$.

\section{MOLECULES AND GENES}

Lis1 and doublecortin (DCX) proteins have been localized to microtubules, suggesting that they are involved in microtubule-dependent nuclear movement ${ }^{399}$. Reelin is an extracellular matrix protein that is secreted from Cajal-Retzius cells and plays a crucial role in the migration of cortical neurons ${ }^{11,14)}$. Without Reelin, neurons fail to detach from the RGC and accumulate underneath the cortical plate.

Fibroblast growth factor (FGF) and its pathway block the maturation of cortical progenitors and promote their proliferation $^{48}$. FGF also plays a role in the self-amplification of cortical progenitors, resulting in cortical expansion ${ }^{42,43)}$. Other important signaling pathways suspected to regulate cortical progenitor proliferation and self-renewal include the Wnt, bone morphogenetic protein (BMP), MAPK, and Notch pathways $^{19,32,38)}$. The Notch pathway and retinoic acid signaling are known to regulate the balance between progenitor proliferation and neurogenesis ${ }^{52}$.

The specific genes associated with cortical malformation are listed in Table 1.

\section{MALFORMATIONS}

The size and folding of the cerebral cortex have a significant impact on brain function and apparently intellectual ability ${ }^{1,211}$. It should be noted that the classification of malformations varies between reports in addition to the one used in this review. For example, microcephaly, megalencephaly, and dysplasias may be classified as malformations of brain size; lissencephaly and polymicrogyria may be classified as cortical folding failure; and subcortical band heterotopia, cobblestone brain, and periventricular heterotopia may be classified as ectopia ${ }^{17)}$. The variation may be caused because many of the anomalies overlap, and the pathomechanisms cannot be simplified into clear-cut categories.

\section{Failure of proliferation/apoptosis}

Alterations in proliferation and survival of the neural progenitor may result in abnormal brain size, namely defective (microcephaly), excessive (megalencephaly), or imbalanced (focal cortical dysplasia [FCD] type II) brain size ${ }^{7}$.

Microcephaly is a rare condition in which affected patients display a significantly small brain size. Genes known to be important for various cellular processes, such as DNA repair efficiency, cell cycle length, mitotic spindle positioning, and centrosome function, are associated with microcephaly ${ }^{56)}$. For instance, microcephalin (MCPH1), which lengthens the cell cycle and alters the alignment of chromosomes, is one of the common causes of primary microcephaly ${ }^{20,25,59)}$. Mutation in

Table 1. Types of human cortical malformation, altered molecular pathway, associated genes

\begin{tabular}{|c|c|c|}
\hline Malformation & Molecular Mechanism & Genes \\
\hline Microcephaly & $\begin{array}{l}\text { DNA repair efficiency/cell cycle length/mitotic spindle } \\
\text { positioning/centrosome maturation, duplication, and } \\
\text { position }\end{array}$ & $\begin{array}{l}\text { MCPH1/ASPM, AKT3/ASPM, STIL, WDR62/NDE1, } \\
\text { CDK5RAP2 }\end{array}$ \\
\hline Megalencephaly & Cell growth & PI3K-AKT signaling AKT3, PIK3R2, PIK3CA \\
\hline Dysplasia & $\begin{array}{l}\text { Cell cycle and growth, ribosome biogenesis, mRNA } \\
\text { translation }\end{array}$ & mTOR pathway activation \\
\hline Lissencephaly type I & Radial migration/cortical lamination & LIS1, DCX, TUBB3, TUBA1A, RELN/RELN \\
\hline Cobblestone (Lissencephaly type II) & Pial surface stability & POMT1, POMT2, FKTN, FKRP \\
\hline Periventricular heterotopia & $\begin{array}{l}\text { Actin cytoskeleton/vesicle trafficking/neuronal } \\
\text { migration/molecular adhesion }\end{array}$ & FNLA, ARFGEF2, C6orf70, FAT4, DCHS1 \\
\hline Polymicrogyria & $\begin{array}{l}\text { Cell adhesion, regulation of phosphorylation, cell } \\
\text { motility, synaptogenesis, angiogenesis/cytoskeleton } \\
\text { regulation/neurite outgrowth }\end{array}$ & SPRX2/GPR56/TUBB2B, TUBB3, TUBA1A/KBP \\
\hline
\end{tabular}

Modified from Fernandez et al. ${ }^{17)}$ with permission. PI3K : phosphatidylinositol 3-kinase, mTOR : mammalian target of rapamycin 
Abnormal Spindle-like, Microcephaly-associated (ASPM), which is important in maintaining the orientation of the mitotic cleavage plane is also found in microcephaly patient $\mathrm{s}^{23,29)}$.

Megalencephaly patients show an abnormally enlarged brain. It is speculated that megalencephaly is caused by the overproduction of progenitor cells and cortical neurons due to a shortened cell cycle that results in increased re-entry into the cell cycle or to decreased apoptosis ${ }^{12,24,58}$. Apart from severe cases, typical megalencephaly cases show excessive cortical folding (polymicrogyria) due to the abundance of progenitor cells $^{6}$. The causal genetic error is under investigation and recent reports suggest that phosphatidylinositol 3-kinase (PI3K)-Akt signaling may play a central role in controlling brain size ${ }^{13,30,45)}$.

FCD is the most common type of malformation of cortical development and frequently presents as epilepsy in children. FCD has two features of malformation, cortical disorganization and the presence of abnormal cells (neuronal heterotopia, balloon cells, neuronal cytomegaly) in abnormal locations ${ }^{37}$. In FCD type II (the subtype with balloon cells or dysmorphic neurons), defective proliferation and/or apoptosis of cortical progenitors seem to be the pathomechanism. mTOR pathway genes are revealed to play important roles in the formation of $\mathrm{FCD}^{3,10}$. In contrast, the pathomechanism of FCD type I is speculated to be organizational failure, such as lack of tangential lamination or abnormal retention of radial cortical pat$\operatorname{tern}^{44)}$.

\section{Failure of migration}

Regulation of variables during migration is critical for the proper positioning of cortical neurons, including both the location and timing of their positioning. In other words, the neurons must migrate through the entire thickness of the cortex and stop at the surface of the cortex ${ }^{17}$. Such a 'fate' is known to be determined by the time and place of their birth. Errors in these events may misplace the neurons, resulting in heterotopias. Heterotopias are described by their appearance (laminar, nodular) and location (periventricular, transcerebral, subcortical, cortical, marginal, and extracortical meningeal).

Lissencephaly includes several types of 'simplified folding pattern' diseases : agyria, pachygyria, and subcortical band heterotopia. Agyria refers to a brain with a complete absence of folds, and pachygyria shows a simplified gyral folding pattern $^{22}$. In subcortical band heterotopia, broad convolutions and a thickened cortex are observed in either a normal or simplified gyral pattern.

Type I or classic type lissencephaly is associated with the mutation of genes related to the cytoskeleton and cell migration. LIS1 or DCX are the most commonly mutated genes ${ }^{39}$. A small portion of type I lissencephaly $(1-4 \%)$ is caused by the mutation of TUBB3 or TUBA1A ${ }^{33}$. Mutations in Reelin (RELN), a critical gene for radial migration and cortical lamination, are also found in a minority of type I patients ${ }^{11,14)}$. These genetic mutations hinder the proper migration of newborn neurons, resulting in the accumulation of neurons below the PP into disorganized and thickened, 4-layer cortex. The thickened cortex is the hallmark finding of lissencephaly, differentiating it from the simplified gyral pattern of primary microcephaly ${ }^{17}$.

Type II lissencephaly or cobblestone brain is different from other migration disorders (caused by undermigration) in that they are formed by overmigration. The anchoring and attachment of the radial glial fibers to the pial membrane is anomalous, resulting in the disruption of the basement membrane. As the cortical basement membrane is the end point of the radial migration of neurons, the disruption leads to the overmigration of the neurons beyond the pia and into the meningeal space. This results in the 'cobblestone' appearance of the cortical surface ${ }^{31,60)}$. There is a wide spectrum of phenotypes, but the known driver genes are related to the attachment of the radial glial fiber to the pial surface or are associated with the glycosylation of alpha-dystroglycan, which is fundamental in the anchoring of the dystrophin complex to the extracellular matrix $^{8,47,55)}$.

Periventricular heterotopia is caused by the failure of the radial migration of cortical neurons. It is speculated that defective remodeling of the actin cytoskeleton inhibits the proper change in cell shape and the locomotion of newborn neurons required for migration. This results in the complete failure of the neurons to depart from the germinal zone, and instead the neurons reside near the ventricular zone clustered into nodules $^{1,49,51)}$. The most frequent genetic alteration in periventricular heterotopia is the mutation of Filamin A (FLNA) and ARFGEF2. FLNA is known to act on the actin skeleton, and ARFGEF2 plays a role in the trafficking of intracellular membranes and vesicles ${ }^{16,18,50)}$.

Polymicrogyria is a group of cortical malformations showing abnormally abundant and small cortical folds and the in- 
terdigitation of white matter causing abnormal lamination ${ }^{7)}$. The polymicrogyria cortex is either 4-layered or unlayered ${ }^{5,57)}$. It is characterized by a malarrangement of the cell layers and intracortical fiber plexus. The excessive folding of the upper or all cellular layers under the continuous smooth molecular layer is also observed. Due to excessive folding, the CP may appear thick, although it is actually thinner than under normal conditions ${ }^{44)}$. The causative genes for polymicrogyria have not been identified; however, associations with several genetic errors, such as mutations in SPRX2 and genes related to the cytoskeleton, have been suggested ${ }^{46)}$.

\section{CONCLUSION}

The development of the cerebral cortex is a complex process involving the proliferation, migration, and differentiation of neural progenitors regulated by multiple genes and molecules in a time- and location-specific manner. A clear understanding of this process will lead us to better understand related malformations, resulting in more effective treatments and preventative therapies for these diseases.

\section{CONFLICTS OF INTEREST}

No potential conflict of interest relevant to this article was reported.

\section{INFORMED CONSENT}

This type of study does not require informed consent.

\section{- Acknowledgements}

This work was supported by Creative-Pioneering Researchers Program through Seoul National University (SNU No. 800-20160282).

\section{References}

1. Andrade DM : Genetic basis in epilepsies caused by malformations of cortical development and in those with structurally normal brain. Hum Genet 126 : 173-193, 2009

2. Anton ES, Marchionni MA, Lee KF, Rakic P : Role of GGF/neuregulin signaling in interactions between migrating neurons and radial glia in the developing cerebral cortex. Development 124 : 3501-3510, 1997

3. Barkovich AJ, Guerrini R, Kuzniecky RI, Jackson GD, Dobyns WB : A developmental and genetic classification for malformations of cortical development: update 2012. Brain 135 : 1348-1369, 2012

4. Barkovich AJ, Kuzniecky RI : Neuroimaging of focal malformations of cortical development. J Clin Neurophysiol 13 : 481-494, 1996

5. Barkovich AJ, Kuzniecky RI, Dobyns WB, Jackson GD, Becker LE, Evrard $P$ : A classification scheme for malformations of cortical development. Neuropediatrics $27:$ 59-63, 1996

6. Barkovich AJ, Kuzniecky RI, Jackson GD, Guerrini R, Dobyns WB : A developmental and genetic classification for malformations of cortical development. Neurology 65 : 1873-1887, 2005

7. Barkovich AJ, Raybaud CA : Malformations of cortical development. Neuroimaging Clin N Am 14 : 401-423, 2004

8. Buysse K, Riemersma M, Powell G, van Reeuwijk J, Chitayat D, Roscioli T, et al. : Missense mutations in beta-1,3-N-acetylglucosaminyltransferase 1 (B3GNT1) cause Walker-Warburg syndrome. Hum Mol Genet 22 : 1746-1754, 2013

9. Bystron I, Blakemore C, Rakic P : Development of the human cerebral cortex: Boulder Committee revisited. Nat Rev Neurosci 9 : 110-122, 2008

10. Crino PB, Nathanson $\mathrm{KL}$, Henske EP : The tuberous sclerosis complex. $\mathbf{N}$ Engl J Med 355 : 1345-1356, 2006

11. D'Arcangelo G, Miao GG, Chen SC, Soares HD, Morgan Jl, Curran T : A protein related to extracellular matrix proteins deleted in the mouse mutant reeler. Nature 374 : 719-723, 1995

12. Dehay C, Kennedy H : Cell-cycle control and cortical development. Nat Rev Neurosci 8 : 438-450, 2007

13. DiLiberti JH : Inherited macrocephaly-hamartoma syndromes. Am J Med Genet 79 : 284-290, 1998

14. Dulabon L, Olson EC, Taglienti MG, Eisenhuth S, McGrath B, Walsh CA, et al. : Reelin binds alpha3beta1 integrin and inhibits neuronal migration. Neuron 27 : 33-44, 2000

15. Elias $L A$, Wang $D D$, Kriegstein $A R$ : Gap junction adhesion is necessary for radial migration in the neocortex. Nature 448 : 901-907, 2007

16. Ferland RJ, Batiz LF, Neal J, Lian G, Bundock E, Lu J, et al. : Disruption of neural progenitors along the ventricular and subventricular zones in periventricular heterotopia. Hum Mol Genet 18 : 497-516, 2009

17. Fernandez V, Llinares-Benadero C, Borrell V : Cerebral cortex expansion and folding: what have we learned? EMBO J 35 : 1021-1044, 2016

18. Fox JW, Lamperti ED, Eksioglu YZ, Hong SE, Feng Y, Graham DA, et al. : Mutations in filamin 1 prevent migration of cerebral cortical neurons in human periventricular heterotopia. Neuron 21 : 1315-1325, 1998

19. Gross RE, Mehler MF, Mabie PC, Zang Z, Santschi L, Kessler JA : Bone morphogenetic proteins promote astroglial lineage commitment by mammalian subventricular zone progenitor cells. Neuron 17 : 595-606, 1996 
20. Gruber R, Zhou Z, Sukchev M, Joerss T, Frappart PO, Wang ZQ : MCPH1 regulates the neuroprogenitor division mode by coupling the centrosomal cycle with mitotic entry through the Chk1-Cdc25 pathway. Nat Cell Biol 13 : 1325-1334, 2011

21. Guerrini R, Dobyns WB, Barkovich AJ : Abnormal development of the human cerebral cortex: genetics, functional consequences and treatment options. Trends Neurosci 31 : 154-162, 2008

22. Guerrini R, Marini C : Genetic malformations of cortical development. Exp Brain Res 173 : 322-333, 2006

23. Gul A, Hassan MJ, Mahmood S, Chen W, Rahmani S, Naseer MI, et al. : Genetic studies of autosomal recessive primary microcephaly in 33 Pakistani families: novel sequence variants in ASPM gene. Neurogenetics $7:$ : 105-110, 2006

24. Hansen DV, Lui JH, Parker PR, Kriegstein AR: Neurogenic radial glia in the outer subventricular zone of human neocortex. Nature 464 : 554561,2010

25. Jackson AP, Eastwood H, Bell SM, Adu J, Toomes C, Carr IM, et al. : Identification of microcephalin, a protein implicated in determining the size of the human brain. Am J Hum Genet 71 : 136-142, 2002

26. Klyachko VA, Stevens CF : Connectivity optimization and the positioning of cortical areas. Proc Natl Acad Sci U S A 100 : 7937-7941, 2003

27. Kriegstein $A R$ : Constructing circuits: neurogenesis and migration in the developing neocortex. Epilepsia 46 Suppl 7 : 15-21, 2005

28. Kriegstein AR, Noctor SC : Patterns of neuronal migration in the embryonic cortex. Trends Neurosci 27 : 392-399, 2004

29. Kumar A, Blanton SH, Babu M, Markandaya M, Girimaji SC : Genetic analysis of primary microcephaly in Indian families: novel ASPM mutations. Clin Genet 66 : 341-348, 2004

30. Lee JH, Huynh M, Silhavy JL, Kim S, Dixon-Salazar T, Heiberg A, et al. : De novo somatic mutations in components of the PI3K-AKT3-mTOR pathway cause hemimegalencephaly. Nat Genet 44 : 941-945, 2012

31. Luo R, Jeong SJ, Jin Z, Strokes N, Li S, Piao X : G protein-coupled receptor 56 and collagen III, a receptor-ligand pair, regulates cortical development and lamination. Proc Natl Acad Sci U S A 108 : 12925-12930, 2011

32. Machon O, van den Bout CJ, Backman M, Kemler R, Krauss S : Role of beta-catenin in the developing cortical and hippocampal neuroepithelium. Neuroscience 122 : 129-143, 2003

33. Morris-Rosendahl DJ, Najm J, Lachmeijer AM, Sztriha L, Martins M, Kuechler $A$, et al. : Refining the phenotype of alpha-1a Tubulin (TUBA1A) mutation in patients with classical lissencephaly. Clin Genet 74 : 425433, 2008

34. Nadarajah B, Parnavelas JG : Modes of neuronal migration in the developing cerebral cortex. Nat Rev Neurosci 3 : 423-432, 2002

35. O'Leary DD, Borngasser D : Cortical ventricular zone progenitors and their progeny maintain spatial relationships and radial patterning during preplate development indicating an early protomap. Cereb Cortex 16 Suppl 1 : i46-i56, 2006

36. Olson EC, Walsh CA : Smooth, rough and upside-down neocortical development. Curr Opin Genet Dev 12 : 320-327, 2002

37. Palmini A, Najm I, Avanzini G, Babb T, Guerrini R, Foldvary-Schaefer N, et al. : Terminology and classification of the cortical dysplasias. Neurology 62(6 Suppl 3) : S2-S8, 2004

38. Phoenix TN, Temple $S$ : Spred1, a negative regulator of Ras-MAPK-ERK, is enriched in CNS germinal zones, dampens NSC proliferation, and maintains ventricular zone structure. Genes Dev 24 : 45-56, 2010

39. Pilz DT, Matsumoto N, Minnerath S, Mills P, Gleeson JG, Allen KM, et al. : LIS1 and XLIS (DCX) mutations cause most classical lissencephaly, but different patterns of malformation. Hum Mol Genet 7 : 2029-2037, 1998

40. Pontious A, Kowalczyk T, Englund C, Hevner RF : Role of intermediate progenitor cells in cerebral cortex development. Dev Neurosci 30 : 2432, 2008

41. Rakic $P$ : A small step for the cell, a giant leap for mankind: a hypothesis of neocortical expansion during evolution. Trends Neurosci 18 : 383388, 1995

42. Rash BG, Lim HD, Breunig JJ, Vaccarino FM : FGF signaling expands embryonic cortical surface area by regulating Notch-dependent neurogenesis. J Neurosci 31 : 15604-15617, 2011

43. Rash BG, Tomasi S, Lim HD, Suh CY, Vaccarino FM : Cortical gyrification induced by fibroblast growth factor 2 in the mouse brain. J Neurosci 33 : 10802-10814, 2013

44. Raybaud C, Widjaja E : Development and dysgenesis of the cerebral cortex: malformations of cortical development. Neuroimaging Clin $\mathbf{N}$ Am 21 : 483-543, vii, 2011

45. Rivière JB, Mirzaa GM, O'Roak BJ, Beddaoui M, Alcantara D, Conway $\mathrm{RL}$, et al. : De novo germline and postzygotic mutations in AKT3, PIK3R2 and PIK3CA cause a spectrum of related megalencephaly syndromes. Nat Genet 44 : 934-940, 2012

46. Roll P, Rudolf $G$, Pereira S, Royer B, Scheffer IE, Massacrier A, et al. : SRPX2 mutations in disorders of language cortex and cognition. Hum Mol Genet 15 : 1195-1207, 2006

47. Roscioli T, Kamsteeg EJ, Buysse K, Maystadt I, van Reeuwijk J, van den Elzen C, et al. : Mutations in ISPD cause Walker-Warburg syndrome and defective glycosylation of alpha-dystroglycan. Nat Genet 44 : 581 585, 2012

48. Sahara S, O'Leary DD : Fgf10 regulates transition period of cortical stem cell differentiation to radial glia controlling generation of neurons and basal progenitors. Neuron 63 : 48-62, 2009

49. Sarkisian MR, Bartley CM, Chi H, Nakamura F, Hashimoto-Torii K, Torii $M$, et al. : MEKK4 signaling regulates filamin expression and neuronal migration. Neuron 52 : 789-801, 2006

50. Sheen VL, Dixon PH, Fox JW, Hong SE, Kinton L, Sisodiya SM, et al. : Mutations in the $X$-linked filamin 1 gene cause periventricular nodular heterotopia in males as well as in females. Hum Mol Genet 10 : 17751783, 2001

51. Sheen VL, Walsh CA : Periventricular heterotopia: new insights into Ehlers-Danlos syndrome. Clin Med Res 3 : 229-233, 2005

52. Siegenthaler JA, Ashique AM, Zarbalis K, Patterson KP, Hecht JH, Kane $M A$, et al. : Retinoic acid from the meninges regulates cortical neuron generation. Cell 139 : 597-609, 2009

53. Sun T, Hevner RF : Growth and folding of the mammalian cerebral cor- 
tex: from molecules to malformations. Nat Rev Neurosci 15 : $217-$ 232, 2014

54. Super $H$, Soriano $E$, Uylings $H B$ : The functions of the preplate in development and evolution of the neocortex and hippocampus. Brain Res Brain Res Rev 27 : 40-64, 1998

55. van Reeuwijk J, Brunner HG, van Bokhoven H : Glyc-0-genetics of Walker-Warburg syndrome. Clin Genet 67 : 281-289, 2005

56. Walsh CA : Genetic malformations of the human cerebral cortex. Neuron 23 : 19-29, 1999

57. Walsh CA : Neuroscience in the post-genome era: an overview. Trends
Neurosci 24 : 363-364, 2001

58. Wang X, Tsai JW, LaMonica B, Kriegstein AR : A new subtype of progenitor cell in the mouse embryonic neocortex. Nat Neurosci 14 : 555-561, 2011

59. Woods CG, Bond J, Enard W : Autosomal recessive primary microcephaly (MCPH): a review of clinical, molecular, and evolutionary findings. Am J Hum Genet 76 : 717-728, 2005

60. Yamamoto T, Kato Y, Karita M, Kawaguchi M, Shibata N, Kobayashi M : Expression of genes related to muscular dystrophy with lissencephaly. Pediatr Neurol 31 : 183-190, 2004 